\title{
The Dynamic Nature of Survival Determinants in E-commerce
}

\author{
Ralitza Nikolaeva*
}

Key words: Survival analysis, order of entry, online retailing.

Acknowledgment: I started working on the topic of survival in e-commerce when I was writing my dissertation at Purdue University. I appreciate the numerous valuable advises I received from Manu Kalwani and Bill Robinson. I would also like to thank Laura Peracchio from UWM for her helpful comments.

\footnotetext{
* Ralitza Nikolaeva is Assistant Professor, School of Business Administration, University of Wisconsin Milwaukee, P.O. Box 742, Milwaukee, WI 53201. Tel. 414-229-3816, fax 414-229-5999, e-mail: nikolar@uwm.edu.
} 


\title{
The Dynamic Nature of Survival Determinants in E-commerce
}

\begin{abstract}
Longitudinal data on 460 e-tailers are used to test the dynamic effects of survival determinants in e-commerce. The model includes elements of competitive strategy, industry structure, firm and product characteristics, and the macro environment. The study demonstrates that very few of the factors affecting survival have a constant effect over time. For example, order of entry advantages are observed, but they are short-lived meaning that etailers cannot rely on early entry as a strategic move in the long run. This finding reconciles the arguments about the existence of pioneering advantages in the empirical literature. Retailers benefit from multiple channels throughout their lives. E-tailers with more media presence also seem to survive longer. Being publicly owned and selling products with digital characteristics present advantages for e-tailers only in the beginning years, but they are not sustainable over long time periods. Survival chances decrease with higher competitive density, market growth rate, and equity market level at the time of entry. Conversely, economic growth tends to increase survival chances. The study also finds an inverted-U relationship between the hazard of exit and firm age. The conclusion section discusses the implications of the time-varying nature of survival determinants.
\end{abstract}

Key words: Survival analysis, order of entry, online retailing. 


\section{Introduction}

It is important to study the evolution of an industry for several reasons. First, it is essential for managers to know at what stage they join the industry, because this will have different implications for their marketing strategies. For example, a growing industry is far more turbulent and risky than a mature one. Second, if managers recognize the effect of certain survival determinants, they can plan better strategies for exit or exit avoidance. For example, more vulnerable firms with unique offerings can seek alliances with bigger companies. Or they can purposefully delay their entry until after the turbulent period in the industry and find a favorable niche in the market. Third, managers need to be aware of the time-varying nature of factors affecting their strategy. A beneficial aspect of the initial entry strategy might diminish its effect over time. Reversely, overcoming some obstacles in the introductory stage may have positive returns in later stages. This calls for an evolutionary perspective on the investigation of survival determinants.

Most of the existing industry evolution studies have looked at the static nature of survival determinants (Agarwal 1997; Klepper 2002). One exception is a study by Agarwal, Sarkar, and Echambadi (2002) looking at contemporaneous effects of survival determinants. In addition, while the concept of strategizing according to the different stages of the PLC has been accepted as a basic postulate in marketing, the time-dependent nature of survival determinants has been largely ignored in the literature. At the same time, survival of online firms has been a subject of considerable debate in the popular and managerial press.

Connecting the missing dots, this study aims at investigating different factors deemed to be important in the online retailing setting (Mahajan, Srinivasan, and Wind 2002; Varadarajan and Yadav 2002). The analysis utilizes population ecology tools popular in the organizational behavior literature. It is based on a longitudinal database of 460 e-tailers examining their entry and possible exit through September 2003. The study employs duration 
models to estimate how elements of competitive strategy, industry structure, firm characteristics, product characteristics, and the macro environment influence e-tailer survival and how these effects change over time. In summary, the contributions of the paper are these:

1. The study provides an empirical test of Varadarajan and Yadav's (2002) theoretical framework.

2. It tests the dynamic nature of the different internal and external factors affecting firms' survival in a duration modeling framework. This allows for the testing of the time-varying nature of both covariates and coefficients - a new approach in the marketing literature.

3. It fills a gap in the order of entry literature by: a) conducting the study in a service industry as opposed to the existing bias in the order of entry literature towards new product introductions (Lieberman and Montgomery 1998) and b) tracing the order of entry effect over time. Further, the use of hazard rate estimation also answers the call of Lieberman and Montgomery (1998) for greater use of such tools, which would "denote a healthy shift away from the excessive emphasis on market share in first-mover studies." (p.1116)

\section{Theoretical Framework}

Varadarajan and Yadav (2002) propose a theoretical framework for integrating the new realities of the Internet into marketing strategy. They describe how various drivers and outcomes of competitive strategy change with the advent of the Internet in business strategies. This theoretical framework is applied to the online retailing setting to explore the dynamic nature of different drivers of firm survival. In most general terms, business performance depends on competitive strategy, industry, firm, product, and buyer characteristics. Buyer 
characteristics serve as a general setting of the model - individual consumers (vs. organizational), diminishing information search cost, diminishing information asymmetry but they are not explicitly modeled. ${ }^{1}$ A sketch of the model is outlined in Figure 1 . The determinants of e-tailer survival are: competitive strategy - order of entry, distribution channels, and publicity; industry structure - number of competitors and market growth rate; firm characteristics - firm age and ownership; product characteristics - products with digital characteristics and search vs. experience goods; macro environment - economic growth and equity market level. The inclusion of some of the variables is also based on the theoretical framework for success in online retailing proposed by Mahajan et al. (2002).

[Insert Figure 1 here.]

Given the dynamic nature of the online marketplace, it is appropriate to explore these determinants in the context of industry evolution. For this purpose, the current study employs a duration model. The incorporation of not only time-varying covariates, but also timevarying coefficients to trace the dynamics of survival determinants is a new methodological approach in marketing. There are several developments like greater information richness and lower information search costs associated with the Internet channel that justify the selection of the factors presented in Figure 1 and the exploration of their dynamic nature (Varadarajan and Yadav 2002). These are discussed in detail in the sections below.

\section{Competitive Strategy}

\section{$\underline{\text { Order of Entry }}$}

It would be safe to say that the idea of first mover advantages permeated the marketing field through the theoretical-analytical economic framework on the subject (e.g. Schmalensee 1982). This framework advanced arguments that first-movers gain advantages because of their ability to raise entry barriers due to scale effects, advertising, consumer 
switching costs, etc. The entry barriers allow pioneers to extend their "natural" monopoly period and thus be able to accrue profits that would later help them successfully fend off competitors. Early marketing studies based on these arguments (Robinson and Fornell 1985; Urban et al. 1986) did find that market pioneers were rewarded by long term market share advantages.

Subsequent studies (Lilien and Yoon 1990; Golder and Tellis 1993) challenged these findings based on survival bias indicating that many true pioneers face the risk of failure. The controversy has continued in more recent studies: Robinson and Min (2002) show that pioneers in industrial markets have higher survival rates compared to second entrants; and Boulding and Christen (2003) conclude that the market share advantage of pioneering is often offset by the greater cost disadvantage.

Taking a different perspective, Kerin, Varadarajan, and Peterson (1992) point out that the order of entry effect is conditional on industry characteristics and strategy variables. Further, there is another largely overlooked factor in the above mentioned studies - the time effect (exceptions are Lilien and Yoon 1990 and Gielens and Dekimpe 2001). The underlying question is not whether first mover advantages exist, but how long they last. Collectively, all of the above studies seem to support the idea that a later entrant with a superior composite product backed by large advertising expenditures can overcome the pioneer. The longer we track industries, the more likely is the entry of a superior late mover (e.g. Golder and Tellis 1993).

In other words, early entrants might be experiencing artificial advantages in the early period after their introduction, which can easily disappear once the industry reaches equilibrium. The following comparison helps to illustrate the above argument. Kalyanaram and Urban (1992) show that later entrants reach their asymptotic market share at a faster rate compared to early entrants. In a sense, this happens because early entrants have to "wait" for 
the late followers to enter, which eventually brings market shares to their asymptotes.

Consequently, during the "waiting" period, early entrants have less competitors and as a result higher market share ${ }^{2}$. Similarly, early entrants may be less prone to early exit, because the market conditions are not so adverse and survival is easier. However, with time and the entry of more competitors, market conditions become more adverse and the advantages enjoyed by early entrants under milder conditions disappear. Since late followers enter under worse market conditions, they tend to exit more often early after their entry and the ones who survive are well equipped to successfully challenge their predecessors. This can be especially relevant for technologically intensive industries (Kerin et al. 1992). Although some followers may be at disadvantage when they enter the industry, they may be better adapters and ultimately even perform better than pioneers. Thus, first mover advantages may be easier to observe in the early stages of a firm's entry into a new industry.

The current study puts the above idea to a test and fills two gaps in the literature. First, it answers two calls by Lieberman and Montgomery (1998) of enhancing the first mover advantage literature - by investigating the online retailing industry it goes away from the product centered research and by employing the evolutionary perspective to investigate the survival of firms it goes away from the emphasis on market share. Second, it traces the order of entry effect over time.

In line with Kerin et al.’s (1992) proposition about the nature of order of entry advantages in technologically intensive industries, it is worthwhile pointing at several characteristics of the online environment that suggest that early entrants' advantages may be short lived. First, the Internet lowers consumer switching costs (Bakos 1997), which has been shown to shorten first mover advantages, because consumers can easily switch to later entrants. In addition, the greater information richness and diminished information asymmetry between buyers and sellers (Varadarajan and Yadav 2002) would make it easier for 
consumers to explore new, unfamiliar options, which can steer them away from early entrants. Accordingly, while consumers might have been hesitant to patronize Overstock.com in the year 2000 (the company launched its store at the end of 1999) in face of the uncertainty about the e-tailer's future, over time the e-tailer managed to attract enough customers with its quality merchandise at closeout prices to become one of the top 20 online retailers in 2004. Second, online retailing has short time periods between entries, which has been shown to shorten first mover advantages (Huff and Robinson 1994). A third factor that points in the same direction is the high market development costs - since the Internet channel was a radical innovation, market development costs are usually high, which can benefit later entrants (Lilien and Yoon 1990). These factors suggest that early mover advantages in online retailing may be limited and dissolve quickly.

Contributing to the diminishing advantage of early entry might be a second generation of entrants - firms that enter after a massive wave of exits and occupy market space vacated by the exitors. Agarwal et al. (2002) cite evidence from prior studies that the mature phase is characterized by a transformational change that drastically alters market conditions in the industry. During the mature phase, the industry infrastructure is well established, knowledge is widespread, and procedures are standardized and routinized. By and large, mature phase entry is at a lower rate and qualitatively different. In the case of e-commerce, the mature phase coincides with a period of low resource munificence (Park and Mezias 2005). Therefore, the wave of late entrants are well prepared to resist turbulences, do not depend on exuberant financing, and come with lessons from the shakeout. In addition, uncertainty is highly reduced compared to the growth phase and incumbents tend to be less responsive to new opportunities because of inertial tendencies. This allows later entrants to find strategic niches and coexist with incumbents who have survived the turbulent period. 
Based on the above arguments, two hypotheses are developed. The first one addresses the order of entry effect and its changing nature over time. The second one follows the theoretical lines of two distinctive industrial regimes cited by Agarwal et al. (2002). It argues that firms who enter after the massive wave of exit of an industry have an advantage.

H1: Order of entry is positively related to e-tailers' probability of exit, but the effect diminishes over time.

H2: Growth phase entrants have a higher probability of exit compared to mature phase entrants.

\section{$\underline{\text { Distribution Channels }}$}

The progress of e-commerce boosted the importance of distribution channels not only as delivery vehicles, but also as communication, trial, and innovation channels. While the electronic channel opened many new opportunities for companies, it also highlighted the value of a physical channel. In reality, not all companies can utilize more than one channel. What is the importance of a multi-channel strategy in online retailing? In the early years of the development of e-commerce, pundits were predicting the dominance of single channel etailers (e-tailers who operate only online stores) over old-economy clicks-and-mortars. Then, after the highly publicized failures of some of the single channel e-tailers, the bets leaned towards multi-channel e-tailers.

Theoretically, multi-channel retailers are expected to fare better. Various studies in economics (Geroski 1995), management (Klepper and Simons 2000), and marketing (Robinson and Min 2002) point out that across different industries entrants who have existing parent companies are more successful. The success is related to the resource base of the parent companies. In addition, Mahajan et al. (2002) theorize that online retailers with existing offline experience would perform better than single-channel e-tailers because of their existing market-based assets that include branding and customer relationships. 
Among the advantages of multi-channel vs. single-channel e-tailers are the opportunity of brand equity transfer, improved customer relationships, and cross-channel synergies. Multi-channel retailers' consumers are already familiar with their brand name. This makes the online extensions more trustworthy. They can benefit from cross-channel promotional activities like incentive offers for their customers to shop online. Showrooms are also a big asset for categories for which touch and feel is important like apparel, furniture, etc. Because of the higher trust factor and existing loyal customers, multi-channel e-tailers may be able to charge higher prices as well. Thus, over time multi-channel firms will have a higher survival probability compared to single channel e-tailers. This yields:

H3: Single-channel e-tailers have a higher probability of exit compared to multi-channel e-tailers.

\section{$\underline{\text { Publicity }}$}

Publicity is part of the promotional mix of companies and is often correlated with advertising spending. Nevertheless, the effect of publicity on company performance is more frequently ignored than accounted for. Duncan and Moriarty (1998) point out that message sources are quite influential in shaping consumers' beliefs about companies. In the Internet specific domain, there are several studies showing the positive relationship between publicity and web site traffic (e.g. Ilfeld and Winer (2002) and Drèze and Zufryden (2004)). Moreover, a research study conducted by AT\&T showed that news coverage is as important as advertising for new customer acquisitions (Jeffries-Fox).

If increased publicity leads to increased web site traffic, then we can expect that higher web site traffic translates into higher sales, which would make e-tailers more viable. In general, publicity is a function of the PR efforts of the company, the company's size and visibility. Companies that are bigger and spend more on advertising are more visible and 
more newsworthy hence they attract more media coverage. All these factors can enhance the survival chances of a firm. This allows for the following hypothesis:

H4: Publicity is negatively related to e-tailers' probability of exit.

\section{Industry Structure}

\section{Competitive Density}

The development of the following hypothesis about the effect of the competitive environment is another response to the call of Lieberman and Montgomery (1998) for "crossfertilization between strategy and marketing” (p.1122). While the strategy and organizational ecology literature have produced prolific studies of population density effects, the marketing literature has paid more attention to the strategic actions of firms. Yet there is no strategic decision that is isolated from the competitive environment and from the particular evolutionary stage of the industry.

In the organizational ecology literature, contemporaneous competitive density (hereafter called competitive density) is the number of competitors in a product category in a given time period. In most general terms, the density-dependent model postulates that the intensity of competition in a population varies according to the number of organizations. Thus, if increasing density increases organizational exit rates, the environment is competitive. On the other hand, if increasing density increases survival rates, this indicates mutualism (Baum and Mezias 1992). Some studies have found a U-shaped relationship between competitive density and failure risk accounting for legitimizing and competitive forces (Carroll and Hannan 1989). The main premise of these studies is that at the initial low population levels, creditors, suppliers, employees, and customers will be cautious when dealing with newly established firms decreasing their survival chances (Aldrich 1999). With the establishment of the industry, survival rates increase until a maximum capacity is reached 
when the market cannot support so many competitors and exit rates increase. Citing a number of organizational studies, Aldrich (1999) points out that the U-shaped relationship is not applicable to all industries.

Perhaps the strongest argument for e-tailing being one of the industries where the theory of a U-shape does not hold is the high environmental munificence marking the formative stages of the industry (Park and Mezias 2005). The period of high munificence confutes the hostile environment characteristic of the early stage of some industries where the U-shaped relationship between population density and exit is observed.

According to economic theory, competition increases on the continuum from monopoly to perfect competition, i.e. ceteris parabus - the higher the number of firms, the higher the competitive intensity. Many empirical studies confirm that price-cost margins tend to be much lower in markets characterized by high number of competitors (Besanko et al. 2003). This yields the following hypothesis:

H5: Competitive density is positively related to e-tailers' probability of exit.

\section{Market Growth Rate}

While growing markets are characterized by increased sales that would imply fewer chances of e-tailers exiting the market, high-growth markets also attract many competitors. Agarwal and Bayus (2002) show that in various industries firm takeoff precedes sales takeoff. This means that markets with high sales growth rates are more competitive. Day, Fein, and Ruppersberger (2003) also observe that high growth markets attract followers who are "naïve about the barriers to entry and don't realize how many others are also poised to enter at the same time" (p.131). In summary, even though the growth of a market increases the size of the pie, it has to be sliced into thinner slices, which leaves the question of the effect of market growth rate on survival open. This leads to two alternative hypotheses:

H6a: Market growth rate is negatively related to e-tailers' probability of exit. 
H6b: Market growth rate is positively related to e-tailers' probability of exit.

\section{Firm Characteristics}

\section{E-tailer Age}

Firm age is another variable that has been heavily used in the strategy/organizations literature, but has been marginalized in marketing. Firm age reflects the experience and organizational knowledge accumulated by a company. Evolutionary models add the caveat that age represents accumulated experience and organizational knowledge in historicallyspecific environments (Aldrich 1999). Subsequent events build on the routines and competences as well as the emotions characteristic of the founding period. They become the standard against which future events are evaluated (Aldrich 1999).

Because many Internet retailers entered during the period of high environmental munificence, their initial endowments were substantial. That might have created a spirit of exuberance not easily matched by subsequent events. Prior research has observed that firms can grow rapidly and adaptively while the initial endowments last and when the endowments are exhausted, growth slows down or some firms may be even forced to exit the industry (Aldrich 1999). This is the basic argument of the liability of adolescence theory (Henderson 1990). Clearly, the situation in the Internet retailing population was similar - with the financial cushion of venture capital or backing from parent companies, exit rates in the formative years are low. As e-tailers burn through their initial capital, exit rates increase over time. Once an equilibrium is achieved, exit rates eventually decline. This scenario is reflected in the following hypothesis:

H7: E-tailer age follows an inverted-U type of relationship with the probability of exit.

\section{E-tailer Ownership}


Since the development of e-commerce was closely associated with the boom and burst of the equity markets, we are bound to investigate the possible differences among publicly traded companies and private ones. Maug (2001) states that publicly owned companies are better off when outside investors have better access to information that is useful for future capital budgeting decisions. These are the cases when industry information is more important. Maug (2001) continues that under these scenarios public firms can use the information aggregated by the stock market and communicated back to the firm by the stock price. Eventually, this information helps the firm make more informed decisions. Since online retailing was a new industry, firms required plenty of outside information to judge its viability. This means that public firms were in a better position.

Another argument in favor of publicly owned companies is their resource base. If the market favors the new technology, as was the case with e-commerce, they can raise even more capital to adopt the new technology. However, this would matter more in the early stages. Once the companies establish themselves, the difference in survival probabilities between public and private companies should disappear. When competition becomes more intense, firm-specific information would be as critical as market-specific information, thus leveling the playing field between public and private companies. Private companies that have survived the turbulent period should not be less viable than public companies. This is supported by many studies cited by Vining and Boardman (1992) that find no difference in profitability between private and public firms. Thus:

H8: Publicly owned e-tailers have a lower probability of exit compared to privately owned e-tailers, but the effect diminishes over time.

\section{Product Characteristics}

$\underline{\text { Products with Digital Characteristics }}$ 
Mahajan et al. (2002) theorize that one of the success factors in e-tailing is selling digital vs. physical products. They define digital products as products that can be digitized and transmitted electronically. Examples include music, electronic books, software, and video. These products can be efficiently distributed online, because they do not require physical space for storage, consumers can get all the information about the products online, and they can be instantaneously delivered electronically. Therefore, these products should do better in the online channel. However, as recognized by Mahajan et al. (2002), the technology has not reached the level where these products are distributed exclusively in their digital form. Another reason for the predominantly physical form of the products is the fear of piracy and easy duplication of the products in their digitized form.

As noted by Varadarajan and Yadav (2002), physical and digital product substitutes may co-exist. Most of the retailers who sell digital products online also sell the products in their physical form. In fact, most of their sales come from the distribution of physical products. Therefore, it is useful to look at the characteristics of the physical substitutes of digital products. We can refer to these products as products with digital characteristics.

These products are standardized, of uniform quality, touch and feel is not important; and they are easy and cheap to ship. Many e-commerce pioneers started selling products in these categories. The universality of the products, however, does not leave much room for differentiation. This implies that the advantages of e-tailers selling products with digital characteristics will dissipate with time. Furthermore, as customers become more comfortable with the online shopping environment, they will be spending more money on products for which touch and feel is important. E-tailers of such products who win customers' trust in their first years of operation should be at an equal footing with e-tailers of products with digital characteristics later on in their lives. This effect of time is incorporated in the next hypothesis: 
H9: E-tailers of products with digital characteristics have a lower probability of exit compared to other e-tailers, but the effect diminishes over time.

\section{$\underline{\text { Search Goods }}$}

The marketing discipline has adopted the classification of Nelson (1970) of search and experience goods in relation to the consumer information search process. Search goods do not need to be examined before purchase, because they can be fully described, whereas experience goods have to be tried by consumers before they are fully evaluated. Since the Internet deprives consumers of the tactility characteristic of products, it becomes even more difficult for consumers to evaluate experience goods. Therefore it should be expected that etailers selling search goods would perform better than e-tailers selling experience goods. This is the argument presented by Mahajan et al. (2002).

On the other hand, Varadarajan and Yadav (2002) propose that for products for which the tactile feedback is important, the opportunity to convey more information over the Internet is likely to benefit the sales of these products. This argument becomes even more valid when customers accumulate sufficient experience with e-tailers. That is why the distinction between search and experience goods might disappear over time. In reality, most products fall on a continuum between search and experience characteristics ${ }^{3}$. If search is on the lower end of the continuum and experience is on the higher, then:

H10: E-tailers' score on the search-experience continuum of products is positively related to their probability of exit, but the effect diminishes over time.

\section{Macro Environment}

\section{$\underline{\text { Economic Growth }}$}


In times of general economic prosperity, firms should find survival easier. Golder and Tellis (2004) hypothesize that a change in the economic environment would cause a change in sales in the same direction. Increasing sales creates a more nurturing environment for firms, which lessens the probability of exit. In a similar line of thought, Baker and Kennedy (2002) document the negative relationship between GDP growth rate and firms' distress delisting rates from the major stock exchanges.

Economic growth is reflected by the equity markets. In the case of Internet retailing, the NASDAQ index played a special role, because it tracks many technology companies. In addition, almost all of the e-commerce companies that issued public stock joined NASDAQ 4 . The NASDAQ index can be also associated with the availability of venture capital. High growth rates are associated with high demand expectations that make venture capitalists relax their criteria and pour more money into new ventures. This would generally mean that periods of high growth in the stock market are associated with greater financial stability that would decrease the chances of failure. This leads to the following hypothesis:

H11: Economic growth is negatively related to e-tailers' probability of exit.

\section{Equity Market Level}

Equity market levels signal market expectations for future demand ${ }^{5}$. Based on the above comments, NASDAQ was a particularly strong signal for e-tailers. Expectations of high growth markets usually attract many entrants to those markets. Day et al. (2003) point out that during the boom period "an unsustainable glut of competitors is attracted by forecasts of high growth and promises of exceptional returns" (p.131). Botman et al. (2004) report several papers in the finance literature documenting that firms that go public during "windows of opportunity" characterized by relatively high equity market levels underperform relative to other offerings. These "opportunity windows" usually arise because of overoptimism about the earnings potential of young growth companies. The authors find a 
positive relationship between market level at the time of offering measured as the average value of the NASDAQ composite index during the month of offering and a firm's hazard of exit (Botman et al. 2004).

The flip side of venture capital availability is that riskier projects get financed, which leads to many premature venture creations. This implies that e-tailers who enter during periods of high growth expectations tend to be less prepared to survive the adjustment period in the industry. However, the ones who utilize their initial endowment wisely and concentrate more on their strategy and operations in their fledgling stages would have higher survival chances later in their lives. Accumulating experience with customers and moving along the learning curve can strengthen the strategic position for companies who entered at times of high growth expectations. This dynamic effect is expressed in the following hypothesis:

H12: A higher equity market level at the time of an e-tailer's entry tends to increase the probability of exit, but the effect diminishes over time.

\section{Data}

The sample has 460 online retailers. Since none of the online retailers entered the market before 1994, the data span January 1994 through September 2003. Because 316 etailers were still in business at the end of the period, the data are right censored. The sample includes all major retailers within a category. The categories are: Apparel, Auto, Books, Computer Software, Computer Hardware, Department Stores, DVDs \& Videos, Electronics, Food \& Drink, Gifts \& Flowers, Health \& Beauty, Home \& Garden, Music, Office Supplies, Pet Supplies, Sports \& Outdoors, Toys \& Video Games.

Based on information from the retailers' web sites, various media sources, Yahoo's finance site, and government statistics, the following data were collected: the month and year 
of entry and exit (where applicable) for each retailer, opening monthly values of the NASDAQ composite index, quarterly GDP growth rate and electronic and mail order sales, number of media mentions from Lexis-Nexis (these are the number of articles and press releases mentioning the company - used to measure the publicity variable in the model), company ownership status, channels, and product categories. A panel of 17 experts marketing faculty members at research universities - were asked to assign a score from $1=$ search to $10=$ experience to the above mentioned product categories. The average of their scores was assigned to the search-experience variable.

The average age of the survivors is 4.65 years. The average life of the e-tailers that exited the industry was 2.28 years with the shortest duration lasting only one month. Table 1 defines the variables along with the means and standard deviations and Table 2 lists the length of the growth stage for the different product categories.

[Insert Table 1 here.]

[Insert Table 2 here.]

By September 2003, 144 retailers had exited the market. A breakdown of survivors and exitors by product category appears in Table 2 . The sample consists of 186 singlechannel Internet retailers (110 of them exited and 76 were still alive) vs. 274 multi-channel retailers (34 exited and 240 were still alive); 236 publicly traded or subsidiaries of publicly traded companies (39 exited, 197 were still alive) vs. 224 private e-tailers (105 exited, 119 were still alive), and 109 e-tailers of products with digital characteristics. In addition, 129 of the 320 e-tailers who entered during the growth stage had exited the industry by the end of the observation period. Table 3 lists the Kaplan-Meyer 1, 2, 5, and 7-year survival rates in these categories as well as the total number of firms who have exited by the end of the observation period and the ones who are still in business. And Table 4 lists the survival rates by order of entry. These descriptive statistics give us some preliminary insights in the hypothesized 
relationships. For example, survival rates decrease with order of entry, but late late entrants' survival rates are almost the same as the survival rates of the whole sample. The dichotomized survival rates show better outcomes for multi-channel, digital products, public retailers and e-tailers that enter the industry during the mature phase.

[Insert Table 3 here.]

[Insert Table 4 here.]

\section{Model Specification and Estimation}

The time to exit the online market space is censored at the end of the observation period. This requires the use of a duration model since standard regression techniques would produce biased results. Since two variables - market growth rate and GDP - are collected on a quarterly basis, the data are organized into discrete groups. Therefore, a discrete time hazard model is a better choice than a continuous time model (Allison 1982). The complementary log-log (cloglog) regression is the discrete time alternative of the Cox proportional hazards regression, which has been used in multiple marketing applications (e.g. Helsen and Schmittlein 1993; Golder and Tellis 2004). The cloglog formulation is commonly used in the population ecology framework (Agarwal et al. 2002; Henderson 1999). There are several advantages of using a cloglog regression. First, it is derived from an inherent continuous process, which means that the estimates are also estimates of the continuous duration model. This also means that the coefficient estimates are invariant to the specification of time intervals (Allison 1982). Second, the discrete time specification avoids some of the estimation hurdles of a continuous time model like ties - multiple firms exiting in the same period of time (a simple derivation of the cloglog link model from a continuous hazard model is available in the appendix of Beck et al. (1998)). Third, the cloglog regression allows the easy incorporation of time-varying covariates. Fourth, it can easily 
incorporate flexible specifications of duration dependence. The cloglog specification appears in Appendix 1.

Another nice feature of the discrete time duration model is that the log-likelihood function has the same form as in a binary regression model, which makes it easy to estimate (see Appendix 1). This estimation, however, requires a re-organization of the dataset. The procedure consists of creating a separate observation for each e-tailer for each quarter. In this way, the unit of analysis becomes firm-quarter rather than firm. For each firm-quarter, we observe the values of the covariates (some of them are fixed and some vary for different quarters) and whether the e-tailer has exited the industry in this quarter or not. If the e-tailer is still in business in a given quarter, then the observation is censored (if an e-tailer is still operating at the end of the observation period, the dependent variable for each firm-quarter observation is 0 ). If, for example, an e-tailer exits in the $7^{\text {th }}$ quarter, then we have 7 firmquarter observations - for the first 6 , the dependent variable is 0 and for the seventh, it is 1 .

Grouping the sample data into discrete quarter intervals results in 7346 firm-quarter observations. In this setting, e-tailer age is the time variable in the duration model - it is identical with the life span variable and we cannot separate the age and time effects (they are used interchangeably). ${ }^{6}$ Even for cases when age dependence is an empirical issue, different scholars in the field suggest using polynomial functions to test age dependence (e.g. Beck et al. 1998; Hannan 1997). The age hypothesis introduced earlier predicts significant effects for a second degree polynomial in e-tailer age.

Further, McCall (1994) points out that the requirement by the Cox proportional hazards regression that the coefficients are constant over time often does not make sense from the point of view of the pertinent theory. Therefore the relevant covariates are interacted with the time variable -e-tailer age. To investigate any non-linearity in the time effect, the covariates were interacted with the age variable as well as the second degree polynomial of 
age. However, none of the second degree polynomial interactions were significant; hence, they are not included in the model. Since the NASDAQ variable is correlated with the order of entry variable $(\mathrm{r}=.78)$, the following two separate cloglog regression equations are estimated $^{7}$ :

$$
\begin{gathered}
\log [-\log (1-h(t))]=\alpha_{0}+\alpha_{1} E A_{i t}+\alpha_{2} E A^{2}{ }_{i t}+\beta_{1} O E_{i}+\beta_{2} O E_{i}^{*} E A_{i t}+\beta_{3} S C_{i}+\beta_{4} P B_{i}+\beta_{5} C D_{t}+ \\
\beta_{6} M G_{t}+\beta_{7} P_{i}+\beta_{8} P_{i}{ }^{*} E A_{i t}+\beta_{9} D_{i}+\beta_{10} D_{i} * E A_{i t}+\beta_{11} S_{i}+\beta_{12} S_{i}^{*} E A_{i t}+\beta_{13} \Delta N_{t}+ \\
\beta_{14} \Delta G D P_{t}
\end{gathered}
$$

$$
\begin{gathered}
\log [-\log (1-h(t))]=\alpha_{0}+\alpha_{1} E A_{i t}+\alpha_{2} E A^{2}{ }_{i t}+\beta_{1} N_{i}+\beta_{2} N_{i} * E A_{i t}+\beta_{3} G_{i}+\beta_{4} S C_{i}+\beta_{5} P B_{i}+\beta_{6} C D_{t} \\
+\beta_{7} M G_{t}+\beta_{8} P_{i}+\beta_{9} P_{i}^{*} E A_{i t}+\beta_{10} D_{i}+\beta_{11} D_{i} * E A_{i t}+\beta_{12} S_{i}+\beta_{13} S_{i}^{*} E A_{i t}+ \\
\beta_{14} \Delta N_{t}+\beta_{15} \Delta G D P_{t}
\end{gathered}
$$

where EA - e-tailer age, $\mathrm{OE}$ - order of entry, SC - single channel, $\mathrm{PB}$ - publicity, CD competitive density, $\mathrm{MG}$ - market growth rate, $\mathrm{P}$ - public, $\mathrm{D}$ - digital products, $\mathrm{S}$ - search goods, $\mathrm{N}$ - NASDAQ, $\triangle \mathrm{N}$ - NASDAQ growth rate, $\Delta \mathrm{GDP}$ - GDP growth rate, G - growth phase entrant, $\mathrm{h}(\mathrm{t})$ - probability of exit, the subscript $i$ stands for e-tailer and $t$ for time period. $^{8}$ Following the theoretical development in the hypotheses part, the modeling of etailer age is the specification of the baseline hazard. Allison (1982) describes how different specifications of the time variable (e-tailer age in this case) correspond to special cases of the discrete time model. For example, if we include the logarithm of the age variable in the model, we assume Weibull distribution of time. The left-hand side of the equation is known as the complementary log-log link (cloglog). The parameters are estimated by maximizing the likelihood function. ${ }^{9}$ For comparison purposes, the model was also estimated using Cox regression with robust standard errors. 


\section{Results}

[Insert Table 5 here.]

Table 5 provides the results for the two models. Wald $\chi^{2}$ is used instead of a likelihood ratio test because of the robust standard error estimations, but the interpretation is similar - a higher statistics indicates a better fitting model. Model fitting information accounting for the number of parameters is also given by the Akaike Information Criterion (AIC) as $-2 \log \Lambda+2 r$, where $\Lambda$ is the likelihood and $r$ is the number of parameters. All things being equal, the model with smaller AIC provides a better fit to the data.

\section{Competitive Strategy}

The impact of order of entry and its interaction with e-tailer age is estimated in Model 1. Since the dependent variable in the cloglog regression is the probability of exit, $\mathrm{H} 1$ predicts a positive sign for the order of entry coefficient, which is confirmed. The negative sign for the interaction of order of entry and e-tailer age indicates that order of entry advantages diminish with time supporting the theory of dissipating pioneering advantages. The hypothesis (H2) that mature phase entrants are more viable than growth stage entrants, is tested in Model 2. The growth phase entrant coefficient is positive and significant at the $10 \%$ level $(\mathrm{p}=0.053)$ indicating weak support for $\mathrm{H} 2$. As discussed, mature phase entrants face different conditions upon entry compared to growth phase entrants, which can help them occupy niches vacated during the preceding big exit wave. In addition, because the industry is less turbulent (meaning lower uncertainty), late entrants may be able to devise better strategies. There is a cautionary note that part of the effect may be due to data censoring. However, we can see that even the 2-year survival rate for growth phase entrants is $80 \%$ vs. $90 \%$ for mature phase entrants. Nevertheless, the issue will benefit from an investigation covering a wider time range. 
As predicted by H3, single channel e-tailers have higher hazard rates. Multi-channel e-tailers' higher survival is helped by the availability of a broader resource base and alternative channels. Pure Internet retailers' lower survival rates might stem from several sources: a limited resources base, hurdles in building a trusted brand, steep learning curve of operating a retail channel, and the general obstacles faced by entrepreneurs in a new population.

E-tailers that receive more media coverage seem to survive longer. Thus, the predicted effect in H4 is confirmed by the statistically significant $(\mathrm{p}=0.014)$ negative coefficient of the publicity variable. While there are some studies showing that higher levels of publicity lead to higher web site traffic (Ilfeld and Winer 2002, Drèze and Zufryden 2004), we need to keep a certain dosage of skepticism regarding the direct link between media coverage and survival rates. It is very likely that bigger e-tailers with bigger marketing expenditures are more frequently mentioned in the media. Because there are no data on these variables, it would be premature to conclude that media presence per se increases survival chance.

\section{$\underline{\text { Industry Structure }}$}

The effect of competitive density on the hazard rate is positive, which confirms hypothesis $\mathrm{H} 5^{10}$. Increasing competition makes resources more scare and subsequently increases failure risk. In addition, increasing population density signals optimistic expectations, which attract poorly prepared or overly optimistic founders - a process that ultimately results in higher exit rates (Aldrich 1999). Increasing competition in the case of online retailers also forced companies to spend a large percentage of their founding capital on inefficient marketing campaigns contributing to their disbanding.

The market growth covariate is positive and significant indicating an increasing hazard of exit with market growth - a support for H6b. This is probably due to the opposing 
forces accompanying the market growth rate - while the market is expanding, the competition is growing as well, which requires higher marketing expenses thus decreasing the survival chance of e-tailers. The preceding argument of a growing market attracting naïve entrepreneurs also explains the observed support for H6b.

\section{$\underline{\text { Firm Characteristics }}$}

The impact of e-tailer age on the hazard rate follows an inverted-U curve, which supports H7. This means that in the very beginning the hazard of exit is low and gradually grows over time until it starts decreasing. This is not surprising in the online retailing context, because many entrants started with big initial endowments. As they deplete their initial endowments, exit chances increase. The ones who survive have had the opportunity to improve their strategies and to redeploy resources in a more efficient way. As they age, the market turbulence is decreasing as well and survival chances increase.

The results confirm H8 - public e-tailers have lower exit rates in the formative years, but with time, the effect diminishes. It seems that the private companies, which manage to overcome the difficulties in the formative years and accumulate sufficient capital do not suffer from any disadvantages compared to public companies. They may be even more flexible once proprietary firm knowledge becomes more crucial for success.

\section{Product Characteristics}

As stated in $\mathrm{H} 9$, e-tailers in categories of products with digital characteristics tend to have lower exit rates in the formative stages. This result is not surprising, because books, music, video, and software were the first products to be sold online. However, as customers become more comfortable with the Internet channel, the distinction disappears. This is confirmed by the latest numbers about online sales - according to data released by ComScore Networks, the fastest growing category of online sales in 2005 was apparel and accessories, which increased by $36 \%$ (press release from 1/5/2006 - www.comscore.com/press/pr.asp). 
The results indicate a marginal support for the search goods hypothesis $-\mathrm{H} 10$. The scale used for the search variable increases from search to experience. Thus, a positive sign of the coefficient means that e-tailers who sell products that stand on the higher end (experience) of the continuum face higher exit rates. The coefficient is significant only in Model 1 and only at the $10 \%$ level $(p=0.079)$. The interaction with age was not supported indicating that the rising popularity of experience goods on the Internet (e.g. apparel) does not seem to be adversely affecting sales of search goods.

\section{$\underline{\text { Macro Environment }}$}

In order to test $\mathrm{H} 11$ predicting a positive relationship between economic growth and survivorship, the model incorporates two variables - the GDP growth rate and the NASDAQ composite index growth rate. In support of H11, both coefficients are negative and highly significant in both models. A better economic milieu and increasing availability of venture capital contribute to lower exit hazards. Since economic growth is tightly related to the level of resources in a particular environment, the results confirm prior findings of the relationship between environmental munificence and firm survival (Park and Mezias 2005).

Looking at the equity market level represented by the fixed NASDAQ values at the time of e-tailer entry, the coefficient estimate in Model 2 is positive and highly significant, which supports the relationship proposed by H12. This means that e-tailers entering during high equity market levels have higher risk of exit. The explanation is in line with Day et al.'s (2003) observation that high demand expectations lured many e-tailers that did not have sustainable business plans to enter the market. These results are consistent with the scenario proposed by Geroski and Mazzucato (2001) that online retailing experienced a speculative bubble, which motivated weak entry and higher exit rates. Also, as suggested in the theoretical development, the effect is not constant over time -the coefficient of the interaction of NASDAQ and e-tailer age is negative and significant. It appears that e-tailers who 
managed to survive the turbulent years were able to narrow the disadvantage gap. For the etailers who entered with solid strategies responding to high demand expectations, the effect dissipates with age.

\section{Summary and Conclusions}

The current study empirically tests Varadarajan and Yadav's (2002) theoretical framework of marketing strategy in the Internet context. This is achieved by investigating how elements of competitive strategy, industry, firm, and product characteristics, as well as the macro environment affect survival of online retailers. The unique feature of the inquiry is that it examines the survival determinants' time-varying nature. To the best of my knowledge, it is the first study in the marketing literature to explore time-varying coefficients in a duration modeling context. Furthermore, the empirical part is based on a manually collected dataset spanning 460 web merchants over a time period of almost 10 years.

The focal point of the competitive strategy variables is the order of entry effect. This answers the call of Lieberman and Montgomery (1998) for more studies on service industries and more studies utilizing duration modeling methods. The results are intriguing, because they come as a reconciliation of the debate in prior studies on the existence of first mover advantages. Order of entry survival advantages are observed only in the formative stages of the industry. Since early entrants have fewer competitors, they are able to enjoy some initial advantages. As time progresses and more competitors enter the market, the pioneering advantages dissipate. In addition, the results suggest that mature stage entrants may be more viable compared to growth stage entrants. The explanation lies in the transformational change occurring in the industry and the vacated market niches after the wave of exits. Retailers entering the industry in the mature phase face a more stable environment and fewer competitors. It is still early to speculate, though, to what extent mature stage entrants will be 
able to learn from the best practices and the mistakes of their predecessors. Managerially, the results demonstrate the fallacy of an early entry strategy as a source of sustainable competitive advantage. Early category entrants like CDNow, E-toys.com, and Garden.com who enjoyed early category leadership are examples of this fallacy.

On the other hand, multi-channel retailers have much higher survival rates compared to single channel retailers and the advantage persists over time. This is consistent with prior findings that entrants with parent companies perform better than de novo entrants do. Multichannel firms have a hedge against adverse conditions in a single channel, have greater financial resources, stronger managerial talent, and established brand equity. Therefore, their survival advantages are not surprising. From a strategy formulation point, single-channel retailers can look for alliances with traditional retailers in their product category. For example, Amazon's alliance with Toys'R'Us allowed the e-tailer to outpace the early category leader E-toys.com.

Investigating the relationship between publicity and survival is another way to proxy for a resource related strategy variable in the absence of better data. The estimated negative coefficient confirms the hypothesis prediction that e-tailers with more media presence have lower exit risk. While publicity by itself can increase web site traffic and consumer trust thus leading to higher longevity, such a conclusion would be hasty in the absence of more data. Until data allow controlling for marketing expenditures and firm size, we cannot disentangle the nature of the publicity effect. Nevertheless, e-tailers can only benefit from a strategically tailored publicity campaign, which aims at maintaining regular communication with media outlets.

Looking at industry structure, the results reveal that exit rates increase with increases in competitive density. According to Baum and Mezias (1992), this is indicative of a competitive environment. The growth of the market both in terms of firms and sales 
increases the hazard of exit, which can be explained by intensified competition, lower margins, and higher marketing expenses. It appears that the high growth market attracted many naïve entrants who were not able to compete successfully in a crowded marketplace. This is to show that entry strategies should be evaluated carefully and even more so during periods of high market growth. Overoptimistic prognoses resulting from a rapidly expanding market can be disastrous to a firm. Managers should be aware that high growth markets heighten the competition.

Age effects are interpreted as accumulation of organizational knowledge. The inverted-U type relationship of exit hazard with e-tailer age is reminiscent of the liability of adolescence theory. The implication is that e-tailers should make wise use of their initial capital and accumulate market experience and knowledge that will be useful after the initial honeymoon period. Publicly traded companies seemed to be more successful during their early developmental stage, because they are in a better position to accumulate and interpret environmental knowledge. Judging by the dissipation of the advantage with time evident in the results, it seems that internal company knowledge and experience become more important as companies age.

Turning to product characteristics, it appears that the advantages of e-tailers selling products with digital characteristics were not long lived either. In the beginning, e-tailers selling books, music, video, and software registered higher survival rates. However, as customers' acceptance of the online channel increased, these e-tailers found it more and more difficult to establish their own niches - many of them were forced to succumb to the power of Amazon.com. Another classification of product categories - a scale for a continuum of search vs. experience characteristics - did not yield conclusive results. There is some evidence to suggest that e-tailers selling products with more search characteristics fare better, but it is not evident across the two models. Furthermore, the hypothesized time effect was 
not observed. These results demonstrate that there are no product categories that have a stronghold in the online channel.

Finally, the effect of macro environmental factors on firm performance should not be underestimated. As expected, economic growth is beneficial to e-tailers. While the GDP is a proxy of the general economic environment, the NASDAQ index growth might be indicative of market expectations and capital availability. High environmental munificence increases etailer survival chances. Another important finding is the positive relationship between the equity market level at the time of entry and e-tailers' exit hazard. The idea that high demand expectations attract premature and weaker entry is not new (Aaker and Day 1986; Day et al. 2003). The current study confirms this hypothesis. Under pressure not to miss a high growth opportunity, new entrants faced the challenge of differentiating themselves from existing etailers and many were not able to do so. Since the most unprepared entrants exit fast, the survival differences decrease over time. Managers who are prepared to meet the ordeals of high-growth markets can expect brighter future at the onset of maturity.

\section{Limitations and Directions for Future Research}

As any empirical study, the current one has its limitations. One of them is the lack of some important variables. The study would have greatly benefited if company information on size and marketing expenditures were available. Such information, however, is not available in the public domain since a big part of the sample are either private companies or subsidiaries of larger public companies who do not provide separate information for their online divisions. Currently the analysis weighs equally the failure of Violet.com with the survival of Amazon.com. It would have been more meaningful within strata of companies of different sizes. Further, there were speculations in the industry press that the main reason for the failure of many e-tailers was their unreasonably high marketing budgets. Data availability 
would have allowed the test of this hypothesis as well as the separation of the publicity effect. Another limitation of the publicity variable is that it lacks any qualitative information, i.e. we do not know whether the articles mentioning an e-tailer are on the positive or negative side. Other data of interest are the type and number of alliances. As Varadarajan and Yadav (2002) point out, one of the new realities of integrating the online channel in the company's strategy is the opportunity of online networks of alliances. Part of the success of Amazon.com is due to the numerous alliances the e-tailer has forged over the years. Thus, the study would have benefited from the inclusion of this variable as well.

Another potential limitation of the study is the interpretation of the stock market effect. While it is true that in more general terms the stock market reflects the general situation of the economy and expectations of market growth, it is a much broader compilation of various factors. This study offers one possible explanation of the NASDAQ effect. It is an interesting effect and future research can certainly delve more into it and offer other explanations.

\section{Conclusion}

Studying the evolution of online retailing illuminates important aspects of marketing strategy in the Internet framework. Most importantly, this research demonstrates that as an industry evolves so do strategic variables. Therefore, marketing strategy should be examined in its dynamic context. From a managerial standpoint, it is important to understand that some factors offering strategic advantages in the formative stages can dissipate over time. Consequently, companies should make the adequate steps in overhauling the change in strategic positions. An example is a strategic variable that has a notable presence in the marketing literature - order of entry advantages. Looking at its dynamic nature, the current study reconciles the existing opposite views on pioneering. There are some order of entry 
advantages, but they are short-lived and e-tailers cannot rely on early entry as a strategic move. This is true even for companies that achieved national brand recognition like Etoys.com and Garden.com. Being first can buy a spot in the hall of fame for some time, but holding on to it requires more than the advantages offered by early entry.

Another important finding is the significant influence of the external environment. It stands as another warning of the perils of high growth markets. Aaker and Day (1986) point out that little can be done to drown the enthusiasm surrounding a high growth industry. When venture capitalists and stock analysts share the enthusiasm, the effect can be particularly detrimental to inexperienced entrepreneurs. Firms that try to cash in during these optimistic markets can be easily forced to exit the market.

Investigating the dynamic nature of survival determinants allows us to see that there are very few factors whose effect does not change with time. For the Internet retailing industry characterized by great transparency, this carries the fundamental implication that companies should constantly reinvent their strategies and operations in search of sustainable competitive advantages. For the research community, the study demonstrates that time effects are important in a dynamic industry and they should not be ignored in future studies. 
Table 1

Variable Definitions, Descriptive Statistics and Correlations ${ }^{*}$

\begin{tabular}{|c|c|c|c|c|c|c|c|c|c|c|c|c|c|c|c|c|}
\hline Variable names and definitions & $\begin{array}{c}\text { Mean } \\
\mathrm{n}=7346 \mathrm{D}\end{array}$ & $\begin{array}{l}\text { Std. } \\
\text { eviation }\end{array}$ & 1 & 2 & 3 & 4 & 5 & 6 & 7 & 8 & 9 & 10 & 11 & 12 & 13 & 14 \\
\hline $\begin{array}{l}\text { 1. Exit }-1 \text { if the company exits in a particular quarter, } 0 \\
\text { otherwise. }\end{array}$ & .02 & .14 & 1 & & & & & & & & & & & & & \\
\hline $\begin{array}{l}\text { 2. Order of Entry - time in fraction of the year after the first } \\
\text { entrant in a category. }\end{array}$ & 3.38 & 1.73 & 0.02 & 1 & & & & & & & & & & & & \\
\hline $\begin{array}{l}\text { 3. Growth Phase Entrant }-1 \text { if date of entry earlier than date of } \\
\text { maximum density, } 0 \text { otherwise. }\end{array}$ & .74 & .44 & 0.05 & -0.42 & 1 & & & & & & & & & & & \\
\hline 4. Single-Channel- 1 for Internet pure retailers, 0 otherwise. & .36 & .48 & 0.12 & -0.15 & 0.37 & 1 & & & & & & & & & & \\
\hline $\begin{array}{l}\text { 5. Publicity - number of media mentions through the life of e- } \\
\text { tailer or through the end of the observation period. }\end{array}$ & 168.12 & 685.74 & -0.02 & -0.07 & 0.08 & -0.01 & 1 & & & & & & & & & \\
\hline $\begin{array}{l}\text { 6. Competitive Density - number of e-tailers in each quarter } \\
\text { relative to the peak number of e-tailers in a category }\end{array}$ & .75 & .24 & 0.07 & 0.43 & -0.19 & -0.10 & 0.02 & 1 & & & & & & & & \\
\hline $\begin{array}{l}\text { 7. Market Growth-moving average of change in electronic and } \\
\text { mail-order sales from previous quarter in millions } \$\end{array}$ & .52 & .45 & 0.04 & -0.13 & 0.14 & 0.13 & -0.00 & 0.02 & 1 & & & & & & & \\
\hline 8. E-tailer Age-quarter-years since time of entry. & 2.34 & 1.77 & -0.02 & -0.38 & 0.15 & -0.03 & 0.07 & 0.22 & -0.25 & 1 & & & & & & \\
\hline 9. Public -1 for publicly owned companies, 0 otherwise. & .54 & .50 & -0.08 & 0.11 & -0.27 & -0.39 & 0.19 & 0.07 & -0.09 & -0.01 & 1 & & & & & \\
\hline $\begin{array}{l}\text { 10. Digital Products - } 1 \text { for products with digital characteristics, } 0 \\
\text { otherwise. }\end{array}$ & .29 & .45 & -0.01 & -0.11 & 0.24 & 0.21 & 0.02 & -0.03 & 0.02 & 0.10 & -0.01 & 1 & & & & \\
\hline $\begin{array}{l}\text { 11. Search-Experience - scale from } 1 \text { to } 10,1 \text { - search, } 10- \\
\text { experience. }\end{array}$ & 5.48 & 1.33 & 0.02 & 0.02 & -0.20 & -0.06 & -0.13 & -0.03 & 0.00 & -0.11 & 0.02 & -0.28 & 1 & & & \\
\hline $\begin{array}{l}\text { 12. NASDAQ - opening value of the NASDAQ composite index in } \\
\text { the month of entry divided by } 1000 \text {. }\end{array}$ & 2.05 & .92 & 0.04 & 0.78 & -0.40 & -0.16 & -0.09 & 0.37 & -0.12 & -0.35 & 0.09 & -0.20 & 0.16 & 1 & & \\
\hline $\begin{array}{l}\text { 13. } \triangle N Q \text { - change in average NASDAQ values from previous } \\
\text { quarter }\end{array}$ & -3.49 & 431.04 & -0.05 & -0.10 & 0.09 & 0.08 & 0.00 & -0.06 & 0.64 & -0.12 & -0.05 & 0.02 & -0.01 & -0.12 & 1 & \\
\hline 14. $\triangle G D P$ change in GDP from previous quarter & 68.01 & 55.91 & -0.04 & -0.12 & 0.08 & 0.07 & 0.01 & -0.15 & 0.51 & -0.07 & -0.03 & 0.03 & -0.01 & -0.15 & 0.17 & 1 \\
\hline
\end{tabular}

\footnotetext{
* The descriptive statistics are based on the reorganized dataset consisting of 7346 firm-quarter observations.
} 
Table 2

Length of growth stage for product categories and category survivors and exits

\begin{tabular}{llrrr}
\hline Product category & $\begin{array}{l}\text { Growth stage in } \\
\text { years }\end{array}$ & Operating & Exits & Total \\
\hline Apparel & 6.75 & 43 & 2 & 45 \\
Auto parts & $3.42^{*}$ & 5 & 0 & 5 \\
Books & 5.83 & 20 & 6 & 26 \\
Department store \& variety & 7.34 & 25 & 8 & 33 \\
Electronics & 5.67 & 26 & 10 & 36 \\
Food \& drink & 5.16 & 19 & 18 & 37 \\
Gifts \& specialty & 4.92 & 17 & 9 & 26 \\
Hardware & 4.42 & 10 & 1 & 11 \\
Health \& beauty & 4.42 & 44 & 27 & 71 \\
Home \& garden & 3.92 & 16 & 9 & 25 \\
Music & 4.91 & 14 & 9 & 23 \\
Office & $0.59 *$ & 4 & 0 & 4 \\
Pets & $0.50^{*}$ & 2 & 2 & 4 \\
Software & 6.09 & 25 & 10 & 35 \\
Sports & 5.08 & 13 & 4 & 17 \\
Toys & 5.25 & 21 & 19 & 40 \\
Video & 4.84 & 12 & 10 & 22 \\
Total & & 316 & 144 & 460 \\
\hline
\end{tabular}

* Only 4-5 firms per category. 
Table 4

Survival rates by order of entry.

\begin{tabular}{ccccccccccccc}
\hline & All & 1 st & 2nd & 3rd & 4 th & 5 th & 6 th & 7 th & 8 th & 9 th & 10 th & $>10$ \\
\hline 1 year & $92 \%$ & $100 \%$ & $100 \%$ & $100 \%$ & $100 \%$ & $100 \%$ & $100 \%$ & $91 \%$ & $94 \%$ & $100 \%$ & $85 \%$ & $89 \%$ \\
2 years & $83 \%$ & $93 \%$ & $94 \%$ & $100 \%$ & $93 \%$ & $93 \%$ & $94 \%$ & $91 \%$ & $78 \%$ & $100 \%$ & $69 \%$ & $79 \%$ \\
5 years & $67 \%$ & $85 \%$ & $76 \%$ & $82 \%$ & $84 \%$ & $80 \%$ & $70 \%$ & $82 \%$ & $56 \%$ & $77 \%$ & $37 \%$ & $67 \%$ \\
7 year & $59 \%$ & $44 \%$ & $63 \%$ & $68 \%$ & $84 \%$ & $72 \%$ & $63 \%$ & $82 \%$ & $56 \%$ & na & na & na \\
\hline $\begin{array}{c}\text { Log-rank test for equality of } \\
\text { survivor functions }\end{array}$ & \multicolumn{2}{c}{ chi2(10)=16.74 } \\
\hline
\end{tabular}


Table 5

Estimation Results $-\mathrm{n}=7346$

\begin{tabular}{|c|c|c|c|c|c|c|c|c|}
\hline \multirow{2}{*}{$\begin{array}{l}\text { Variables and Hypotheses } \\
\text { Constant }\end{array}$} & \multicolumn{2}{|c|}{$\begin{array}{l}\text { Model } 1 \\
\text { Cloglog coefficient } \\
\text { estimates } \\
\text { (robust st. err.) }\end{array}$} & \multicolumn{2}{|c|}{$\begin{array}{l}\text { Model 1 } \\
\text { Cox coefficient } \\
\text { estimates } \\
\text { (robust st. err.) }\end{array}$} & \multicolumn{2}{|c|}{$\begin{array}{l}\text { Model } 2 \\
\text { Cloglog coefficient } \\
\text { estimates } \\
\text { (robust st. err.) }\end{array}$} & \multicolumn{2}{|c|}{$\begin{array}{l}\text { Model 2 } \\
\text { Cox coefficient } \\
\text { estimates } \\
\text { (robust st. err.) }\end{array}$} \\
\hline & -8.24 & $(0.76)^{* * *}$ & -- & & -9.47 & $(0.76)^{* * *}$ & -- & \\
\hline Order of entry (H1) & 0.27 & $(0.14)^{* *}$ & 0.25 & $(0.13)^{*}$ & -- & & -- & \\
\hline Order of entry*E-tailer age (H1) & -0.12 & $(0.05) * *$ & -0.11 & $(0.05)^{* *}$ & -- & & -- & \\
\hline Growth phase (H2) & -- & & -- & & 0.62 & $(0.32)^{*}$ & 0.63 & $(0.32)^{* *}$ \\
\hline Single-channel (H3) & 1.65 & $(0.24)^{* * *}$ & 1.65 & $(0.24)^{* * *}$ & 1.50 & $(0.25)^{* * *}$ & 1.50 & $(0.25)^{* * *}$ \\
\hline Publicity (H4) & -0.001 & $(0.001)^{* *}$ & -0.002 & $(0.001)^{* *}$ & -0.002 & $(0.001)^{* *}$ & -0.002 & $(0.001)^{* *}$ \\
\hline Competitive density (H5) & 2.01 & $(0.68) * * *$ & 2.10 & $(0.66)^{* * *}$ & 1.73 & $(0.66)^{* * *}$ & 1.79 & $(0.63)^{* * *}$ \\
\hline Market growth (H6) & 1.71 & $(0.52)^{* * *}$ & 1.52 & $(0.48)^{* * *}$ & 1.71 & $(0.53)^{* * *}$ & 1.48 & $(0.49)^{* * *}$ \\
\hline E-tailer age (H7) & 0.72 & $(0.32)^{* *}$ & -- & & 1.12 & $(0.33)^{* * *}$ & -- & \\
\hline E-tailer age $^{2}(\mathrm{H} 7)$ & -0.12 & $(0.04) * * *$ & -- & & -0.15 & $(0.04) * * *$ & -- & \\
\hline Public (H8) & -1.20 & $(0.38) * * *$ & -1.15 & $(0.38)^{* * *}$ & -0.99 & $(0.40)^{* *}$ & -0.96 & $(0.39)^{* *}$ \\
\hline Public*E-tailer age (H8) & 0.39 & $(0.11)^{* * *}$ & 0.37 & $(0.11)^{* * *}$ & 0.35 & $(0.12)^{* * *}$ & 0.34 & $(0.12)^{* * *}$ \\
\hline Digital (H9) & -1.18 & $(0.36)^{* * *}$ & -1.14 & $(0.35)^{* * *}$ & -1.07 & $(0.38)^{* * *}$ & -1.02 & $(0.37)^{* * *}$ \\
\hline Digital*E-tailer age (H9) & 0.33 & $(0.12) * * *$ & 0.30 & $(0.12)^{* *}$ & 0.27 & $(0.12)^{* *}$ & 0.24 & $(0.12) * *$ \\
\hline Search $(\mathrm{H} 10)$ & 0.11 & $(0.06)^{*}$ & 0.11 & $(0.06)^{*}$ & 0.10 & $(0.06)$ & 0.10 & $(0.07)$ \\
\hline GDP growth (H11) & -0.01 & $(0.002)^{* * *}$ & -0.01 & $(0.002)^{* * *}$ & -0.01 & $(0.002)^{* * *}$ & -0.01 & $(0.002)^{* * *}$ \\
\hline NASDAQ growth (H11) & -1.69 & $(0.46)^{* * *}$ & -1.56 & $(0.37)^{* * *}$ & -1.61 & $(0.41)^{* * *}$ & -1.39 & $(0.36)^{* * *}$ \\
\hline NASDAQ (H12) & -- & & -- & & 0.73 & $(0.16)^{* * *}$ & 0.83 & $(0.17)^{* * *}$ \\
\hline NASDAQ*E-tailer age (H12) & -- & & -- & & -0.27 & $(0.09) * * *$ & -0.31 & $(0.10)^{* * *}$ \\
\hline LL & & 564.87 & & 997.63 & & 559.88 & & 691.84 \\
\hline Wald $\chi^{2}$ & & 88.53 & & 63.46 & & 42.36 & & 300.75 \\
\hline AIC & & 61.74 & & 21.25 & & 53.76 & & 411.68 \\
\hline
\end{tabular}

*** Coefficients significant at $1 \%, * *-5 \%, *-10 \%$ 
Figure 1

Factors Affecting E-tailer Survival ${ }^{1}$

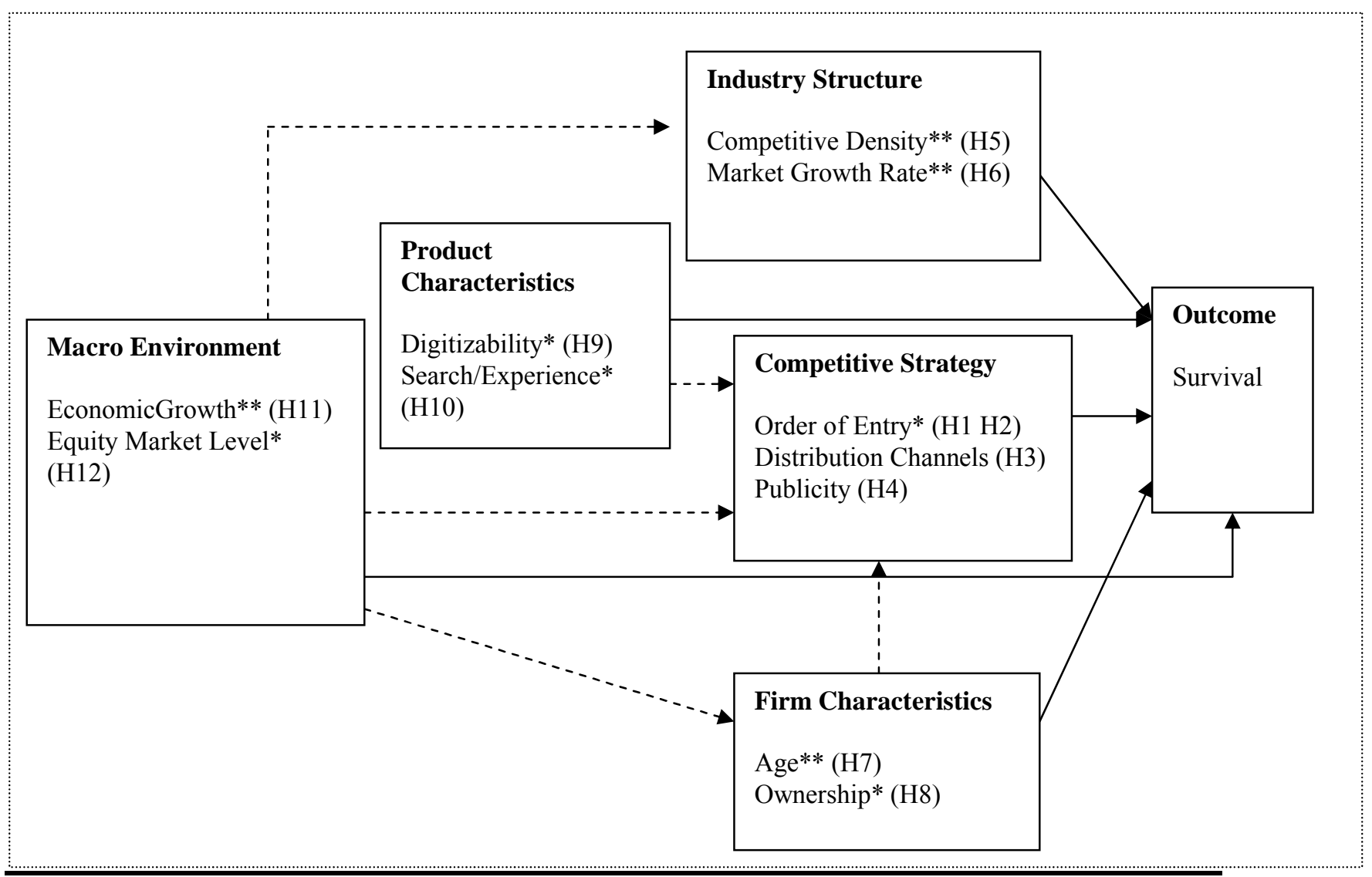

${ }^{1}$ Based on the conceptual framework of Varadarajan and Yadav (2002). Dotted relationships are not included in the current model. See endnote 1 for additional comments.

* Time-varying coefficient; ** Time-varying covariate. 
Figure 2

Entry and exit of e-tailers

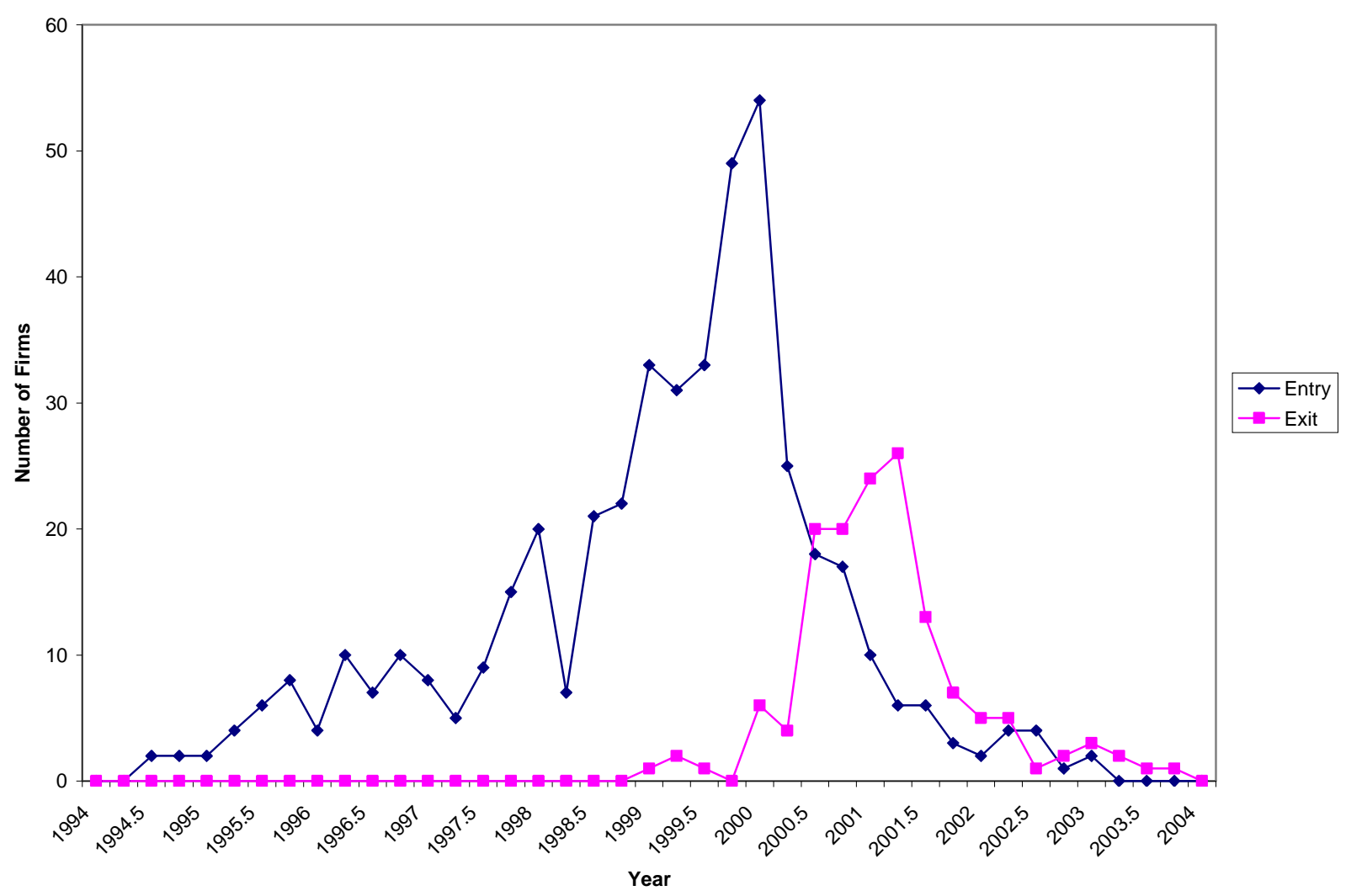




\section{Appendix 1}

The Cloglog Model

The hazard rate is the probability of failure in the next interval of time conditional on surviving to that time:

$$
h_{i t}=\operatorname{Pr}\left(T_{i}=t \mid T_{i} \geq t ; X_{i t}\right)
$$

where $X_{i t}$ is a vector of covariates for firm $i$ at quarter $t$ that may vary with time and $T$ is the discrete random variable indicating the time when a firm exits the industry. Since there are 38 quarters in the data, $t$ assumes values from 1 to 38 . Deriving the probability from the continuous proportional hazards regression, we have:

$$
h_{i t}=1-\exp \left[-\exp \left(\alpha_{t}+X_{i t} \beta\right)\right]
$$

which can be re-written as the cloglog function:

$$
\log \left[-\log \left(1-h_{i t}\right)\right]=\alpha_{t}+X_{i t} \beta
$$

where $\alpha_{t}$ is the baseline hazard. This is identical to the continuous proportional hazards model where we have the following expression for the hazard function:

$$
\log h(t, X)=\alpha_{t}+X_{i t} \beta
$$

In both cases $\alpha_{t}$ is an unspecified function of time. Specifying $\alpha_{t}$ is in fact specifying the probability distribution of time. For example, if $\alpha_{t}$ is a constant, then we have the exponential distribution. The flexibility of the discrete formulation allows us also to express $\alpha_{t}$ as a polynomial in $t$.

The likelihood function can be written as:

$$
L=\prod_{i=1}^{n}\left[\operatorname{Pr}\left(T_{i}=t_{i}\right)\right]^{\delta_{i}}\left[\operatorname{Pr}\left(T_{i}>t_{i}\right)\right]^{1-\delta_{i}}
$$

where $\delta_{i}$ is a censoring indicator which equals 1 if the observation is uncensored and 0 if it's censored. The appropriate substitutions to arrive to the log-likelihood function, which is the 
same as the one for regression analysis of dichotomous dependent variable are shown in Allison (1982):

$$
\log L=\sum_{i=1}^{n} \sum_{j=1}^{t_{i}} y_{i j} \log \left[h_{i j} /\left(1-h_{i j}\right)\right]+\sum_{i=1}^{n} \sum_{j=1}^{t_{i}} \log \left(1-h_{i j}\right)
$$

where $y_{i j}$ equals one if a firm exits in time $j$, zero otherwise, i.e. for survivors it is 0 for all periods and for the firms that exit, it is 0 for all periods up to the one in which they exit, when $y$ becomes 1 . Thus, we have constructed the likelihood function of a standard binary dependent variable model $\left(y_{i j}\right)$ with all the underlying assumptions where the unit of analysis is firm-quarter. In this way, we can use standard software to estimate the model, the only requirement being the different organization of the data. 


\section{References}

Aaker, David A. and George S. Day. 1986. "The Perils of High-Growth Markets.” Strategic Management Journal 7 (5): 409-421.

Agarwal, Rajshree. 1997. "Survival of Firms Over the Product Life Cycle.” Southern Economic Journal 63 (3): 571-585.

and Barry L. Bayus. 2002. "The Market Evolution and Sales Take-off of Product Innovations.” Management Science 48 (8): 1024-1041.

--------, MB Sarkar, and Raj Echambadi. 2002. “The Conditioning Effect of Time on Firm Survival: An Industry Life Cycle Approach.” Academy of Management Journal 45 (5): 971-994.

Aldrich, Howard. 1999. Organizations Evolving. Thousand Oaks, CA: Sage Publications. Allison, Paul. 1982. "Discrete-Time methods for the Analysis of Event Histories." Sociological Methodology 13: 61-98.

Baker, George and Robert E. Kennedy. 2002. "Survivorship and the Economic Grim Reaper." Journal of Law Economics and Organization 18 (2): 324-361.

Bakos, Yannis. 1997. "Reducing Buyer Search Costs: Implications for Electronic Marketplaces.” Management Science 43 (12): 1676-92.

Baum, Joel A. and Stephen J. Mezias. 1992. "Localized Competition and Organizational Failure in the Manhattan Hotel Industry, 1898-1990." Administrative Science Quarterly 37 (4): 580-604.

Beck, Nathaniel, Jonathan N. Katz, and Richard Tucker. 1998. "Taking Time Seriously: Time-Series-Cross-Section Analysis with a Binary Dependent Variable.” American Journal of Political Science 42 (4): 1260-1288.

Besanko David, David Dranove, Mark Shanley, and Scott Schaefer. 2003. Economics of Strategy. 3rd edn, Wiley: New York. 
Botman, Michiel, Tjalling van der Goot, and Noud P.A. van Giersbergen. 2004. "What Determines the Survival of Internet IPOs?” Discussion Paper: 2004/09. Universiteit van Amsterdam.

Boulding, William and Markus Christen. 2003. "Sustainable Pioneering Advantage? Profit Implications of Market Entry Order.” Marketing Science 22 (3): 371-392.

Cappellari, Lorenzo and Stephen P. Jenkins. 2003. "Multivariate Probit Regression Using Simulated Maximum Likelihood." Stata Journal 3(3): 278-294.

Carroll, Glenn R. and Michael T. Hannan. 1989. "Density Delay and the Evolution of Organizational Populations: A Model and Five Empirical Tests.” Administrative Science Quarterly 34 (3): 411-430.

Chain Store Age Executive. 1997. "Store-based Retailers Are Testing the Waters of Net Commerce.” June: 10-11.

Day, George S., Adam J. Fein, and Gregg Ruppersberger. 2003. "Shakeouts in Digital Markets: Lessons from B2B Exchanges.” California Management Review 45(2): 131150.

Drèze, Xavier and Fred Zufryden. 2004. "Measurement of Online Visibility and Its Impact on Internet Traffic.” Journal of Interactive Marketing 18 (1): 20-37.

Duncan, Tom and Sandra Moriarty. 1998. “A Communication-Based Marketing Model for Managing Relationships.” Journal of Marketing 62 (2): 1-13.

Geroski, Paul A. 1995. “What Do We Know about Entry?” International Journal of Industrial Organization 13 (4): 421-440.

------- and Mariana Mazzucato. 2001. "Modeling the Dynamics of Industry Populations.” International Journal of Industrial Organization 19 (7): 1003-1022. 
Gielens, Katrijn and Marnik Dekimpe. 2001. "Do International Entry Decisions of Retail Chains Matter in the Long Run?" International Journal of Research in Marketing 18 (3): $235-259$.

Golder, Peter N. and Gerard J. Tellis. 1993. „Pioneer Advantage: Marketing Logic or Marketing Legend?” Journal of Marketing Research 30 (2): 158-170.

------. 2004. “Going, Going, Gone: Cascades, Diffusion, and Turning Points of the Product Life Cycle." Marketing Science 23 (2): 180-191.

Hannan, Michael. 1997. "Inertia, Density and the Structure of Organizational Populations: Entries in European Automobile Industries, 1886-1981." Organization Studies 18(2): 193-228.

Helsen, Kristiaan and David C. Schmittlein. 1993. "Analyzing Duration Times in Marketing: Evidence for the Effectiveness of Hazard Rate Models.” Marketing Science 12 (4): 395-414.

Henderson, Andrew. 1999. "Firm Strategy and Age Dependence: A Contingent View of the Liabilities of Newness, Adolescence, and Obsolescence.” Administrative Science Quarterly 44 (2): 281-314.

Huff, Lenard and William Robinson. 1994. "The Impact of Leadtime and Years of Competitive Rivalry on Pioneer Market Share Advantages.” Management Science 40 (10): 1370-77.

Ilfeld, Johanna and Russel Winer. 2002. “Generating Website Traffic.” Journal of Advertising Research 42 (5): 49-61.

Jeffries-Fox, Bruce. "Toward An Understanding of How News Coverage and Advertising Impact Consumer Perceptions, Attitudes and Behavior.” Institute for Public Relations. Available: http://www.instituteforpr.com/pdf/news-advertising.pdf. Accessed on: $07 / 19 / 2005$. 
Kalyanaram, Gurumurthy, and Glen L. Urban. 1992. "Dynamic Effects of the Order of Entry on Market Share, Trial Penetration, and Repeat Purchases for Frequently Purchased Consumer Goods.” Marketing Science 11 (3): 235-50.

Kerin, Roger, P. Rajan Varadarajan, and Robert Peterson. 1992. "First-Mover Advantage: A Synthesis, Conceptual Framework, and Research Propositions.” Journal of Marketing $56(4): 33-52$.

Klepper, Steven. 2002. "Firm Survival and The Evolution of Oligopoly." The Rand Journal of Economics 33 (1): 37-61.

and K. L. Simons. 2000. "Dominance by Birthright: Entry of Prior Radio Producers and Competitive Ramifications in the U.S. Television Receiver Industry.” Strategic Management Journal, 21 (10-11): 997-1016.

Lieberman, Marvin and David Montgomery. 1998. "First-Mover (Dis)Advantages:

Retrospective and Link with Resource-Based View." Strategic Management Journal, 19 (12): 1111-1125.

Lilien, Gary and Eunsang Yoon. 1990. "The Timing of Competitive Market Entry: An Exploratory Study of New Industrial Products.” Management Science 36 (5): 568-85. Mahajan, Vijay, Raji Srinivasan, and Jerry Wind. 2002. "The Dot.com Retail Failures of 2000: Were There Any Winners?" Journal of the Academy of Marketing Science, 30 (4): 474-486.

Maug, Ernst. 2001. "Ownership Structure and the Life-Cycle of the Firm: A Theory of the Decision to Go Public.” European Finance Review 5 (3): 167-200.

Menard, Scott. 2001. Applied Logistic Regression Analysis (Sage University Paper Series on Quantitative Applications in the Social Sciences, 07-106). Thousand Oaks, CA: Sage. McCall, B. P. 1994. "Testing the Proportional Hazards Assumption in the Presence of Unmeasured Heterogeneity." Journal of Applied Econometrics 9 (3): 321-334. 
Nelson, Phillip. 1974. “Advertising as Information.” The Journal of Political Economy 82 (4): 729-754.

Ofek, Eli and Matthew Richardson. 2002. "The Valuation and Market Rationality of Internet Stock Prices." Oxford Review of Economic Policy 18 (3): 265-287.

Park, Namgyoo and John M. Mezias. 2005. "Before and After the Technology Sector Crash: The Effect of Environmental Munificence on Stock Market Response to Alliances of E-Commerce Firms.”Strategic Management Journal 26 (11): 987-1007.

Robinson, William and Claes Fornell. 1985. "Sources of Market Pioneer Advantages in Consumer Goods Industries.” Journal of Marketing Research 22 (3): 305-17. and Sungwook Min. 2002. "Is the First to Market the First to Fail? Empirical Evidence for Industrial Goods Businesses.” Journal of Marketing Research 39 (1): 120-128. Schmalensee, Richard. 1982. "Product Differentiation Advantages of Pioneering Brands." American Economic Review 72 (3): 349-65.

Tellis, Gerard, J. and Peter N. Golder. 1996. "First to Market, First to Fail? Real Causes of Enduring Market Leadership.” Sloan Management Review 37 (2): 65-75.

Urban, Glenn, Theresa Carter, Steven Gaskin, and Zofia Mucha. 1986. “Market Share Rewards to Pioneering Brands: An Empirical Analysis and Strategic Implications.” Management Science 32 (6): 645-659.

USA Today. 1999. "Shopping showdown headed on line.” September 13: 3B.

Varadarajan, P. Rajan and Manjit S. Yadav. 2002. "Marketing Strategy and the Internet: An Organizing Framework." Journal of the Academy of Marketing Science 30 (4): 296312.

Vining, Aidan R. and Anthony E. Boardman. 1992. “Ownership versus Competition: Efficiency in Public Enterprise.” Public Choice 73 (2): 205-239. 


\section{Endnotes}

${ }^{1}$ There are two reasons for not including buyer characteristics in the model. First, there are no specific publicly available data. Second, in terms of strategy formulation and performance outcomes, buyer characteristics tend to be industry specific. Thus, a study conducted in a single industry would not exhibit great variation in buyer characteristics. Examples of such buyer or buying environment characteristics provided by Varadarajan and Yadav (2002) include individual vs. organizational, non-trivial information search costs, low cost transparency, one to many vs. many to many communication models, etc.

${ }^{2}$ It is important to note that early entry advantages are not purely a function of less competition. The formative stages of an industry are associated with legitimacy issues. Thus, switching to competitors may bear higher risks for consumers than at later stages. For example, it was riskier to switch from Amazon to a competitor 10 years ago than it is today. Other factors that can contribute to early movers' advantages during the "waiting" period are technology cost and know-how, better financing, as well as some harder to imitate features. ${ }^{3}$ It is important to note that products with digital characteristics are not necessarily falling on the search end of the continuum. For example, books and movies have to be consumed before full evaluation is possible. In confirmation of this observation, the correlation in the sample between digital and search is $28 \%$.

${ }^{4}$ In their sample of 382 Internet-related IPOs Botman et al. (2004) register only 13 firms that were not listed on NASDAQ. In the sample used for the current study, $45 \%$ of the publicly traded companies are listed on NASDAQ with only one of the single-channel e-tailers not being listed on NASDAQ. Exemplary of the trading activity of e-commerce firms is a quote from Ofek and Richardson (2002, p.266): "For example, consistently through the 1998-2000 
period, pure-play Internet firms represented as much as 20 percent of the dollar volume in the public equity market even though their market capitalization never exceeded 6 percent." ${ }^{5}$ I am grateful to Steven Klepper for this suggestion.

${ }^{6}$ The separation of age and time effects has been a complex issue in the organizational literature. Generally, time effects can be separated into age, cohort, and period effects. For a detailed discussion, the reader is directed to Aldrich's chapter on organizations and social change (Aldrich 1999). Interpreting the pure effects of aging, cohorts, and periods, as noted by Aldrich (1999), requires sophisticated research designs and coverage of long periods of populations' history, which is not the goal of the current study. The main goal of evolutionary analysis is to study transformation in organizations through time. In this sense, the age variable in the model serves as a proxy for the transformations experienced by firms. ${ }^{7}$ In general, there are no ready-made solutions to the multicollinearity problem. Among the most often suggested solutions are either variable transformation or not including one of the correlated variables in the model (Menard 2001). Since no variable transformations solved the collinearity problem between the order of entry and the NASDAQ variables, the variables are modeled in two separate equations. While this is not a perfect solution, it is a way to show the effect of both variables on the survival probabilities of e-tailers. To test whether this approach introduces any unobserved biases, a random effects model was estimated, but it did not indicate the presence of unobserved heterogeneity (see also endnote 8 ).

${ }^{8}$ As mentioned earlier, some relationships in Varadarajan and Yadav’s (2002) organizing framework (the dotted lines in Fig. 1) are not included in the model. This can create a potential problem with endogeneity since the errors of the covariates are not independent any more. Following Cappellari and Jenkins (2003), a multivariate probit model was estimated to test for cross-equation correlations (the code from the authors is available for free download). 
This method is used to test for possible endogeneity between the different elements of the model. For example, elements of competitive strategy may be dependent on other variables in the model like product and firm characteristics or the macro environment. For this purpose, the equations are estimated jointly and the effect of the endogenous variables is captured by the cross-equation correlations. None of the cross-equation correlations was significant, which increases the confidence that the model used in the current study is not misspecified. As another precaution, the model is estimated accounting for unobserved firmspecific factors assuming Gamma-distributed unobserved heterogeneity. Since the value of the Gamma variance is virtually $0(0.000045)$, there are no signs of unobserved heterogeneity and the model is estimated as described in the Model section of the paper.

${ }^{9}$ The STATA 8.0 option "cluster" was used for the estimation of robust standard errors to account for dependency of firm-quarter observations. It is an extension of the Huber-White sandwich robust variance estimator. For the purpose, the data are partitioned into groups corresponding to the 460 observations - such that the observations are correlated within groups, but not across them. The estimated variance-covariance matrix is the following:

$$
\hat{V}=\hat{\mathbf{V}}\left(\sum_{K=1}^{M} \mathbf{u}_{k}^{(G)} \mathbf{u}_{k}^{(G)}\right) \hat{\mathbf{V}}
$$

where $\hat{\mathbf{V}}$ is the estimator for the variance of maximum likelihood estimates and $\mathbf{u}_{k}^{(G)}$ is the contribution of the $k$ th e-tailer (Buckley and Westerland 2004).

${ }^{10}$ A model testing the U-shape relationship found in some studies was estimated. However, the multicollinearity caused by the presence of the quadratic term is quite severe resulting in unreliable coefficient estimates. Nevertheless, a plot of the empirical logits against the competitive density variable suggests that the effect is best approximated by a linear relationship. 